\title{
Similar acute physiological responses from effort and duration matched leg press and recumbent cycling tasks
}

\author{
James Steele Corresp., $^{1,2}$ ， Andrew Butler ${ }^{1}$ ， Zoe Comerford ${ }^{1}$, Jason Dyer ${ }^{1}$, Nathan Lloyd ${ }^{1}$, Joshua Ward ${ }^{1}$, \\ James Fisher $^{1}{ }^{\text {, Paulo Gentil }}{ }^{3}$, Christopher Scott $^{4}$, Hayao Ozaki ${ }^{5}$ \\ ${ }^{1}$ School of Sport, Health, and Social Sciences, Southampton Solent University, United Kingdom \\ 2 ukactive Research Institute, ukactive, London, United Kingdom \\ 3 Faculty of Physical Education, Federal University of Goiás, Brazil \\ 4 Department of Exercise, Health, and Sport Sciences, University of Southern Maine, United States \\ 5 Graduate School of Health and Sports Science, Jutendo University, Japan \\ Corresponding Author: James Steele \\ Email address: james.steele@solent.ac.uk
}

The present study examined the effects of exercise utilising traditional resistance training (leg press) or 'cardio' exercise (recumbent cycle ergometry) modalities upon acute physiological responses. Nine healthy males underwent a within session randomised crossover design where they completed both the leg press and recumbent cycle ergometer conditions. Conditions were approximately matched for effort and duration (leg press: $4 \times 12 \mathrm{RM}$ using a 2 second concentric and 3 second eccentric repetition duration controlled with a metronome, thus each set lasted $\sim 60$ seconds; recumbent cycle ergometer: 4 × 60 second bouts using a resistance level permitting 80-100 rpm but culminating with being unable to sustain the minimum cadence for the final 5-10 seconds). Measurements included $\mathrm{VO}_{2}$, respiratory exchange ratio (RER), blood lactate, energy expenditure, muscle swelling, and electromyography. Perceived effort was similar between conditions and thus both were well matched with respect to effort. There were no significant effects by 'condition' in any of the physiological responses examined (all $p>$ 0.05). The present study shows that, when both effort and duration are matched, resistance training (leg press) and 'cardio' exercise (recumbent cycle ergometry) may produce largely similar responses in $\mathrm{VO}_{2}$, RER, blood lactate, energy expenditure, muscle swelling, and electromyography. It therefore seems reasonable to suggest that both may offer a similar stimulus to produce chronic physiological adaptations in outcomes such as cardiorespiratory fitness, strength, and hypertrophy. Future work should look to both replicate the study conducted here with respect to the same, and additional physiological measures, and rigorously test the comparative efficacy of effort and duration matched exercise of differing modalities with respect to chronic improvements in physiological fitness. 
1 Title: Similar acute physiological responses from effort and duration matched leg press and recumbent cycling tasks

2

3 Authors: James Steele ${ }^{\mathrm{a}, \mathrm{b}}$, Andrew Butler ${ }^{\mathrm{a}}$, Zoe Comerford ${ }^{\mathrm{a}}$, Jason Dyer ${ }^{\mathrm{a}}$, Nathan Lloyd ${ }^{\mathrm{a}}$, Joshua Ward ${ }^{\mathrm{a}}$, James

4 Fisher $^{\mathrm{a}}$, Paulo Gentil ${ }^{\mathrm{c}}$, Christopher Scott ${ }^{\mathrm{d}}$, Hayao Ozaki ${ }^{\mathrm{e}}$

5

6 a School of Sport, Health, and Social Sciences, Southampton Solent University, UK,

7 bukactive Research Institute, ukactive, London, UK

8 'Faculty of Physical Education, Federal University of Goiás, Brazil,

9 dDepartment of Exercise, Health, and Sport Sciences, University of Southern Maine, USA,

$10{ }^{\mathrm{e}}$ Graduate School of Health and Sports Science, Jutendo University, Japan

11

12 Corresponding author:

13 James Steele (james.steele@solent.ac.uk)

14 School of Sport, Health and Social Science

15 Southampton Solent University,

16 East Park Terrace,

17 Southampton

18 Hampshire,

19 SO14 0YN 
$\underline{\text { Abstract }}$

32 The present study examined the effects of exercise utilising traditional resistance training (leg press) or 'cardio' exercise (recumbent cycle ergometry) modalities upon acute physiological responses. Nine healthy males underwent a within session randomised crossover design where they completed both the leg press and recumbent cycle ergometer conditions. Conditions were approximately matched for effort and duration (leg press: 4 x 12RM using a 2 second concentric and 3 second eccentric repetition duration controlled with a metronome, thus each set lasted $\sim 60$ seconds; recumbent cycle ergometer: 4 × 60 second bouts using a resistance level permitting 80-100 rpm but culminating with being unable to sustain the minimum cadence for the final 5-10 seconds). Measurements included oxygen consumption $\left(\mathrm{VO}_{2}\right)$, respiratory exchange ratio (RER), blood lactate, energy expenditure, muscle swelling, and electromyography. Perceived effort was similar between conditions and thus both were well matched with respect to effort. There were no significant effects by 'condition' in any of the physiological responses examined (all $p>0.05$ ). The present study shows that, when both effort and duration are matched, resistance training (leg press) and 'cardio' exercise (recumbent cycle ergometry) may produce largely similar responses in $\mathrm{VO}_{2}$, RER, blood lactate, energy expenditure, muscle swelling, and electromyography. It therefore seems reasonable to suggest that both may offer a similar stimulus to produce chronic physiological adaptations in outcomes such as cardiorespiratory fitness, strength, and hypertrophy. Future work should look to both replicate the study conducted here with respect to the same, and additional physiological measures, and rigorously test the comparative efficacy of effort and duration matched exercise of differing modalities with respect to chronic improvements in physiological fitness. 


\section{$\underline{\text { Introduction }}$}

Physical activity and exercise appears to offer protection against all-cause mortality (Nocon et al., 2008; Paffenberger

et al., 1986) in a seemingly dose-response fashion (Byberg et al., 2009; Lee and Skerrett, 2001; Loprinzi, 2015a).

Thus, public health guidelines currently recommend the accumulation of a minimum duration of physical activity and/or exercise per week (a combination of 30 minutes of moderate [50-70\% max heart rate] five times per week and/or 20 minutes of vigorous [70 - $80 \%$ max heart rate] three times per week; Haskell et al., 2007). The efficacy of these recommendations could be considered disappointing in view of recent studies, showing that only a marginal reduction in all-cause mortality occurs when they are met (Lee et al., 2011; Wen et al., 2011; Loprinzi, 2015a). However, evidence is accumulating that outcome measures such as cardiorespiratory fitness (Lee et al., 2011; Wen et al., 2011 ; Kodama et al., 2009; Loprinzi, 2015b), strength (Buckner et al., 2015; Leong et al., 2015; Loprinzi and Loenneke, 2016; Loprinzi, 2016; Newman et al., 2006; Ruiz, et al., 2008; Strand et al., 2016), and muscle mass (Srikanthan and Karlamangla, 2014; Srikanthan et al., 2016) may be stronger predictors of health and longevity. Further, there is growing evidence of the potential efficacy of higher intensity of effort approaches, and so the paradigmatic shift in thinking towards an effort, rather than cumulative volume, driven model is beginning (Biddle and Batterham, 2015; Phillips and Winett, 2010; Steele et al., 2017a).

The primary focus of investigations regarding higher effort exercise approaches has been colloquially termed 'cardio' exercise modalities (i.e. locomotive and ambulatory modes such as cycling, running, rowing, incline walking, and stairclimbing; Biddle and Batterham, 2015; Phillips and Winett, 2010; Steele et al., 2017a). It has recently been argued however, that resistance training (i.e. free weights, resistance machines, bodyweight/callisthenic exercises, resistance bands, etc.) may be a modality that also fits the higher effort paradigm as it is typically performed at a relatively high effort, for a relatively brief duration, and relatively infrequently (Steele et al., 2017a). Effort in resistance training has been defined as being determined primarily by proximity to momentary failure (i.e. when the demands of the exercise match or exceed the current ability to meet those demands; Steele et al., 2017b; Steele et al., 2017c; Steele, 2014). 
85

86

87

88

89

90

91

92

93

94

95

96

97

98

99

100

101

102

103

104

105

106

107

108

109

110

111

112

person, can be created with a variety of protocols, and is not dependent upon a specific amount of external force." Indeed, a more encompassing definition of effort is that it is the perception associated with attempting to achieve a particular demand, or set of demands, and which is determined by the current ability to meet the task demands relative to those demands. As such, this conceptualisation of effort could also be applied across exercise modalities (e.g. proximity to task failure in cycling) to better understand whether they impart similar or differential physiological effects Historically, resistance training modalities and 'cardio' training modalities have been dichotomised with respect to the physiological stimulus they provide and chronic adaptations they produce (Nader, 2006). Indeed, signalling pathways responsible for the typical adaptations that seem to occur from either modality are apparently separate (Atherton et al., 2005). It has, however, been proposed that exercise modality may have little impact upon acute responses or adaptations assuming intensity of effort is similarly high (Fisher and Steele, 2014).

The adaptations in cardiorespiratory fitness typically thought to occur as a result of modalities of exercise such as cycling also have been reported to occur as a result of resistance training, though primarily if intensity of effort is sufficiently high (i.e. to momentary failure; Steele et al., 2012) and seemingly irrespective of the manipulation of other variables (i.e. load, set volume, rest periods, and frequency; Ozaki et al., 2013a). Conversely, the adaptations in strength and hypertrophy thought typically to occur from resistance training modalities of exercise have been found to occur as a result of aerobic modalities (Konopka and Harber, 2014), though again this seems primarily to be the case if they are performed with a high effort (i.e. combined with blood flow restriction, or with close proximity to failure such as interval training or sprinting; de Oliviera et al., 2016; Lundberg et al., 2013; Ozaki et al., 2015; Ozaki et al., 2013b). Despite this, studies directly comparing resistance training and 'cardio' training modalities upon these chronic adaptations contrast in their findings with some showing certain adaptations to be similar (Messier and Dill, 1985; Sawczyn et al., 2015; Hepple et al., 1997; Jubrias et al., 2001) and others showing some adaptations to differ (Hepple et al., 1997; Jubrias et al., 2001; Farup et al., 2012; Goldberg et al., 1994; Wilkinson et al., 2008). These contrasting findings though may be due to the manner in which comparisons have been made. Indeed most comparisons have lacked parity in variables such as effort and duration. As noted, effort may be of importance and where this has been controlled between interventions (e.g. 'high intensity interval training' and high effort resistance training), recent work suggests that there may be little difference in the adaptations produced (Androulakis-Korakakis et al., 2017; Álvarez et al., 2017). 
114 Many of the physiological responses may be similar between exercise modes, assuming variables such as intensity of

115 effort are controlled, and if this is the case, different modes may therefore result in similar adaptations. For example,

116 it is thought that, similarly to 'cardio' modalities, resistance training to a high intensity of effort results in maximal

117 aerobic and anaerobic metabolism, and as such local working muscle oxygen utilisation $\left(\mathrm{VO}_{2}\right)$ and lactate production

118 (Steele et al., 2012). Indeed, when matched for physiological effort (at the load/power eliciting individual ventilatory

119 threshold/onset of blood lactate accumulation at $4 \mathrm{mmol.L^{-1 }}$ ), resistance training modalities (half squats and bench

120 press) have been shown to elicit similar acute $\mathrm{VO}_{2}$ to 'cardio' modality exercise (lower and upper body cycling

121 (Vilaca-Alves et al., 2016). Further, high effort resistance training increases muscle water content (Giessing et al.,

122 2016; Ribiero et al., 2014) resulting in muscle swelling that appears to be largely independent of external load

123 (Loenneke et al., 2016). As such it is perhaps unsurprising that high effort aerobic modalities also increase muscle

124 water content (Mora-Rodriguez et al., 2016) and result in muscle swelling (Ozaki et al. 2013b). In consideration of

125 Henneman's size principle, motor unit recruitment should also be similar between muscular actions when they are

126 performed to a near maximal effort (Potvin and Fuglevand, 2017) and indeed this has been argued to be the case for

127 resistance training whether performed at high or low loads (Fisher et al., 2017a; Vigotsky et al., 2017). Thus it might

128 be expected that low force/load 'cardio' modalities might also produce high motor unit recruitment if performed with

close proximity to momentary failure and thus high effort. However, in many studies of typical 'cardio' modes of exercise peak electromyographical amplitudes only achieve $\sim 10-50 \%$ of maximum voluntary contraction (Ericson et al., 1985; Marsh and Martin, 1995). Further, normalised electromyographic amplitudes appear to be greater during typical resistance training (single leg knee extension) compared with 'cardio' mode (single leg cycle ergometry) exercise performed to volitional failure (Noble et al., 2017). Although, time to task failure in Noble et al. (2017) was unclear and amplitude based analyses may not reflect the entirety of motor units recruited where task durations differ, particularly if differing recruitment patterns are occurring (i.e. sequential recruitment of low to high threshold during low force tasks, and simultaneous recruitment of both low and high threshold motor units during high force tasks;

137 Fisher et al., 2017a; Vigotsky et al., 2017; Potvin \& Fuglevand, 2017; Enoka and Duchateau, 2015). However, where units may occur (Kuznetsov et al., 2011). 
142 It seems that there may be greater similarity in the physiological responses to differing exercise modes than assumed 143 under the typical historical dichotomisation of resistance training and 'cardio' training. Indeed the conceptualisation 144 of exercise from the perspective of an effort based model (Steele et al., 2017a; Fisher and Steele, 2014) hypothesises that exercise modality may have little impact upon acute responses or adaptations assuming intensity of effort is high. The practical implications of this are considerable as it suggests that persons wishing to attain the greatest health and fitness benefits from engaging in exercise may be able to choose based upon personal preference from a wide range of possible modalities to produce a similar physiological stimulus, so long as intensity of effort is high. However, though studies independently report many responses to be similar, studies conducting direct comparisons of resistance training and 'cardio' exercise modalities using ecologically valid approaches (i.e. reflecting typical training approaches employed in real word settings) are lacking. Previous studies comparing acute responses to effort matched resistance training and 'cardio' exercise modalities have either not matched protocols employed for duration or used approaches that are not representative of typical exercise programs (Vilaca-Alves et al., 2016; Noble et al., 2017; Kuznetsov et al., 2011). Considering this, the aim of the present study was to examine the effects of training utilising traditional resistance training (leg press) or 'cardio' exercise (recumbent cycle ergometry) modalities whilst attempting to approximately control for effort and duration within ecologically valid protocols, upon acute physiological responses $\left(\mathrm{VO}_{2}\right.$, respiratory exchange ratio [RER], blood lactate, energy expenditure, muscle swelling, and electromyography). It was hypothesised that, when effort and duration are matched, the two modalities would result in similar acute physiological responses.

\section{Materials and Methods}

162

163

\section{Ethical Approval}

The study was approved by the Health, Exercise, and Sport Science ethics committee at Southampton Solent University (ID No. 316) and was conducted in accordance with the Declaration of Helsinki.

\section{Study Design}

A within session randomised crossover design was adopted to examine the acute physiological effects of two difference exercise modes; resistance training (leg press) and 'cardio' exercise (recumbent cycle ergometry). The 
169

170

171

172

173

174

175

176

177

178

179

180

181

182

183

184

185

186

187

188

189

190

191

192

193

194

195

196

within session design was used to reduce measurement error occurring across session's (particularly for electromyography and ultrasound) and a randomised counterbalanced order used to mitigate any order effects and resultant fatigue. The two exercise modes were chosen to reflect the typical ecologically valid conceptualisation of what constitutes high effort 'resistance training' and what constitutes high effort 'cardio exercise'. Attempts were made to approximately match the effort and duration of both conditions whilst reflecting ecologically valid high effort approaches to the performance of either mode. Thus the resistance training mode involved performance of 4 sets of 12 repetition maximum (RM; using a 2 second concentric and 3 second eccentric duration - thus $\sim 60$ seconds total per set), and the aerobic exercise mode involved 4 sets of sprints lasting 60 seconds in duration using a resistance meaning the participants could not sustain the required cadence $(80 \mathrm{rpm})$ by the end of the set. Both conditions allowed 4 minutes rest between sets. $\mathrm{VO}_{2}$ and RER were examined during the exercise and rest periods, blood lactate was measured at the end of each exercise period, energy expenditure was estimated for both the exercise and rest periods, muscle swelling was measured pre and post both conditions, and electromyography was measured throughout the exercise periods.

\section{$\underline{\text { Participants }}$}

Nine healthy male adult participants were recruited for the study. Participants were recreationally active but had not been involved in any structured exercise interventions for the previous 6 months. Exclusion criteria included; unstable angina, recent cardiac infarction, uncompensated heart failure, severe valvular illness, pulmonary disease, uncontrolled hypertension, kidney failure, orthopaedic/neurological limitations to exercise, cardiomyopathy, scheduled operations during the study period, current drug or alcohol abuse, or current participation in a parallel study. All participants were provided with a participant information sheet and gave written informed consent. Participant demographics are shown in Table 1.

\section{$\underline{\text { Equipment }}$}

Height was measured using a wall mounted stadiometer (Holtan ltd, Crymych, Dyfed), body mass measured using digital scales (Life Measurement Inc, Concord, California, USA) and Body Mass Index (BMI) calculated. Resting blood pressure was measured whilst seated using an automated sphygmomanometer (Bosch \& Sohn Germany, Jungingen, Germany). Expired gases were measured using a Viasys Oxycon Pro on-line gas analysis system (Jaeger, 
197 Germany). Blood lactate measures were made using a Biosen C Line blood analyser (EKF Diagnostic, Germany).

198 Muscle swelling was determined from measurements of muscle thickness using an M7 Diagnostic Ultrasound System

199 (Shenzhen Mindray Bio-Medical Electronics Co. Ltd., China). Electromyography (EMG) was measured using a

200 Trigno Digital Wireless EMG System (Delsys,USA). Perceived effort and discomfort were also recorded for each

201 exercise condition using two separate 11 point scales to examine whether perceived effort was similar between

202 conditions (Steele et al., 2017c). This was in order to avoid the cofounding effects of participants anchoring perceived

203 effort upon perceived discomfort when traditional rating of perceived exertion scales are used without instruction to

204 differentiate the two. The exercise conditions were performed using a Nautilus Nitro Evo Leg Press (Nautilus,

205 Vancouver, USA) and a Cybex 530R Recumbent Cycle Ergometer (Cybex, UK).

206

207

$\underline{\text { Participant Testing Procedures }}$

208 Participants were required to visit the laboratory for 2 testing sessions separated by 3-5 days. On the first session 209 participants underwent testing in a randomised counterbalanced order to determine the leg press 12RM loads and recumbent cycle ergometer resistance levels to be used during the second testing session. A rest period of 20 minutes was permitted between each test. For 12RM determination participants first performed a set of 12 repetitions using a

212 load of $\sim 50 \%$ their estimated 12RM. Participants were then subsequently permitted up to maximum of 5 attempts with

2134 minutes of rest permitted between attempts to determine the 12RM load to be used for the leg press. Repetitions were performed using a using a 2 second concentric and 3 second eccentric repetition duration controlled with a metronome. Thus the $12 \mathrm{RM}$ that was determined permitted $\sim 60$ seconds in total of time under load. For determination of recumbent cycle ergometer resistance level participants first performed 60 seconds of cycling at the lowest resistance level at $\sim 60 \mathrm{rpm}$. Participants were then permitted up to a maximum of 5 attempts with 4 minutes of rest permitted between attempts to determine the resistance level (ranging 1 to 20) that would permit them to cycle for 60 seconds between $80-100 \mathrm{rpm}$ culminating in failure to maintain a minimum cadence of $80 \mathrm{rpm}$ over the final 5-10 seconds of the sprint.

222 On the second testing session participants underwent testing for acute physiological responses to both the leg press and recumbent cycle ergometer in a randomised counterbalanced order. Attempts were made to match the effort and duration of exercise performed in each condition and both the leg press and recumbent cycle were chosen in order to 
225 approximately match the musculature and positioning during each condition. A rest period of 20 minutes was

226 permitted between each condition.

227

228

230

231

232

233

234

236

237

238

239

240

241

242

243

244

245

246

247

The leg press condition involved participants performing 4 sets of 12RM. Repetitions were performed using a 2 second concentric and 3 second eccentric repetition duration controlled with a metronome. Thus each set lasted $\sim 60$ seconds in total. If participants could not perform all 12 repetitions then the load was decreased for the next set by $\sim 5 \%$. If participants were able to exceed all 12 repetitions then the load was increased for the next set by $\sim 5 \%$. A rest of 4 minutes was permitted between each set.

The recumbent cycle ergometer condition involved participants performing 4 sets of sprints lasting 60 seconds in duration. The resistance level was set so that participants could cycle between 80-100 rpm but such that each set culminated in the participants being unable to sustain the minimum cadence. If participants could not sustain the required minimum cadence $(80 \mathrm{rpm})$ prior to the last 5-10 seconds of the set then the resistance level was decreased by 1 for the next set. If participants still exceeded the required minimum cadence $(80 \mathrm{rpm})$ over the last 5 - 10 seconds of the set then the resistance level was increased by 1 for the next set. A rest of 4 minutes was permitted between each set.

\section{$\underline{V O}_{2}$, RER, Blood Lactate, and Energy Expenditure}

Expired gases were collected throughout both the entirety of each condition, including both exercise and rest periods, and for a further 4 minutes rest post completion of the final set of either condition. Both mean and peak $\mathrm{VO}_{2}$ and $\mathrm{RER}$ were examined for each set, rest period, and also the averages across sets, rest periods, and the entire duration of each condition. Capillary blood samples were taken at rest and immediately post each set of exercise in each condition.

This was performed using the procedures outlined by Maughan et al (2011). The tip of the participant's middle finger on their non-dominant hand was cleaned using an alcohol wipe and then allowed to air dry. The skin on the prepared area finger was then punctured using a disposable lancet and the first drop of blood wiped away using a clean tissue. Capillary sampling tubes and eppendorf containers were used to collect samples for analysis. Blood lactate analysis was performed once all samples had been collected. Because of the nature of the exercise conditions performed, both total aerobic and total anaerobic energy expenditure estimates were made from mean $\mathrm{VO}_{2}$ across each period and both 
253

254

255

256

257

258

259

260

261

262

263

264

265

266

267

268

269

270

271

272

273

274

275

276

277

278

279

280

rest and exercise blood lactate data. This was conducted for each set, rest period, and also the totals across sets, rest periods, and the entire duration of each condition. Estimates were calculated following the approaches described by Scott and Reis (2016) for calculating total energy cost for a given task. It should be noted that for one participant during the leg press condition, and one participant during the recumbent bike condition, the online gas analysis system failed to record data.

\section{Muscle Swelling}

Muscle swelling was determined from the thickness of the quadriceps $\left(\mathrm{Q}_{t}\right)$ of the right leg measured using B-mode ultrasound. Participants were instructed to avoid any strenuous physical activity or exercise for at least 3-5 days prior to the acute testing session to avoid acute swelling. Measurements were taken twice at rest prior to the first exercise condition, at 4 minutes post completion of the first exercise condition, after the additional 20 minutes of rest between exercise conditions, and at 4 minutes post completion of the second exercise condition. The participant was placed in a supine position with a pillow placed in the popliteal fossa to relax the upper thigh. The scanning site was identified as the mid-point of the distance from the greater trochanter to the mid-point of the lateral knee joint line. A $7.5 \mathrm{MHz}$ linear array transducer was placed perpendicular to the long axis of the thigh in order to obtain a frozen real-time image of the quadriceps. Measurement of $\mathrm{Q}_{t}$ was made in centimetres using the built-in digital callipers measuring the vertical distance from the superficial fat-muscle interface to the underlying femur. Care was taken to ensure adequate contact gel was used and minimal pressure applied to minimise distortion to underlying tissue. All images were be taken by one operator. Intra-operator reliability was determined from using the two baseline measures using standard error of measurement (SEM). The SEM was used to reflect the variation of an individual's measured values upon repeated testing in order to determine the minimum required observable change in repeated measures to be confident an intervention was responsible. Intra-operator SEM for $\mathrm{Q}_{\mathrm{t}}$ was $0.36 \mathrm{~cm}$. It should be noted that for one participant it was not possible to obtain a clear enough quadriceps ultrasound image.

\section{Electromyography}

Electromyography was measured for the rectus femoris of the right leg of each participant during each exercise period. Electrode placement was made following the recommendations from the Surface Electromyography for the Noninvasive Assessment of Muscles (SENIAM) project (http://www.seniam.org/). Participant's skin was shaved and then 
281

282

283

284

285

286

287

288

289

290

291

292

293

294

295

296

297

298

299

300

301

302

303

304

305

306

307

308

cleaned using an alcohol-free cleansing wipe at the site used for electrode placement. Raw signals were collected at $2000 \mathrm{~Hz}$ and root mean square (RMS) rectified. Peak and mean RMS amplitudes, in addition to integrated electromyography (iEMG; calculated as $\mu \mathrm{V} \cdot \mathrm{s}$ using the trapezoidal method) were calculated for each set and as an average across each condition. It should be noted that for one participant for both conditions, and one participant during set 4 in the recumbent bike condition, the electromyography system failed to record data

\section{Data Analysis}

The independent variables were the set or rest period (1,2,3, and 4), and the exercise condition (leg press or recumbent cycle ergometer). Dependent variables were peak and mean $\mathrm{VO}_{2}$, peak and mean RER, blood lactate, anaerobic, aerobic, and total energy expenditure, $\mathrm{Q}_{t}$, peak and mean RMS amplitude, iEMG, and both perceived effort and discomfort. Shapiro-Wilk tests were used to examine assumptions of normality of distribution at $p>0.05$. For all dependent variables except $\mathrm{Q}_{\mathrm{t}}$, within condition comparisons for exercise and rest periods for data meeting assumptions of normality of distribution were made using two way (set/rest period $\mathrm{x}$ condition) repeated measures analysis of variance (ANOVA; a Greenhouse-Geisser correction was applied where assumptions of sphericity were found to be violated using Mauchly's test) and post hoc pairwise comparisons with a Bonferroni correction. Data violating assumptions of normality of distribution was rank transformed for comparison using two way repeated measures ANOVA. Data for $\mathrm{Q}_{\mathrm{t}}$ met assumptions of normality of distribution and so between conditions comparisons were made using paired samples $t$-tests. Statistical analysis was performed using IBM SPSS Statistics for Windows (version 22; IBM Corp., Portsmouth, Hampshire, UK) and $p \leq .05$ set as the limit for statistical significance.

\section{$\underline{\text { Results }}$}

\section{$\underline{V_{2}}, 2$ RER, Blood Lactate, and Energy Expenditure}

For the exercise periods two way repeated measures ANOVA revealed no significant effects by 'set' for mean $\mathrm{VO}_{2}$ $\left(F_{(3,15)}=1.633, p=0.224\right)$, peak $\mathrm{VO}_{2}\left(F_{(3,15)}=2.000, p=0.157\right)$, or aerobic energy expenditure $\left(F_{(3,15)}=1.873, p=\right.$ 0.178). Significant effects by 'set' were found for mean $\operatorname{RER}\left(F_{(3,15)}=4.908, p=0.014\right)$, peak RER $\left(F_{(3,15)}=3.650, p\right.$ $=0.037)$, blood lactate $\left(F_{(3,15)}=23.645, p<0.001\right)$, anaerobic energy expenditure $\left(F_{(3,15)}=20.178, p<0.001\right)$, and total energy expenditure $\left(F_{(3,15)}=18.114, p<0.001\right)$. There were no significant effects by 'condition' for mean $\mathrm{VO}_{2}$ $\left(F_{(1,5)}=3.825, p=0.108\right)$, peak $\mathrm{VO}_{2}\left(F_{(1,5)}=1.077, p=0.347\right)$, mean $\operatorname{RER}\left(F_{(1,5)}=2.219, p=0.197\right)$, peak RER $\left(F_{(1,5)}\right.$ 
$309=1.676, p=0.252)$, blood lactate $\left(F_{(1,5)}=0.130, p=0.733\right)$, aerobic energy expenditure $\left(F_{(1,5)}=2.552, p=0.171\right)$,

310 anaerobic energy expenditure $\left(F_{(1,5)}=0.179, p=0.690\right)$, or total energy expenditure $\left(F_{(1,5)}=0.331, p=0.590\right)$.

311 Significant 'set $x$ condition' interactions were found only for mean $\operatorname{RER}\left(F_{(3,15)}=4.944, p=0.014\right)$ where it tended to

312 be higher during the first two sets in the recumbent cycle ergometer condition.

313

314 For the rest periods two way repeated measures ANOVA revealed no significant effects by 'set' for peak $\mathrm{VO}_{2}\left(F_{(3,15)}\right.$

$315=1.135, p=0.367)$. Significant effects by 'set' were found for mean $\operatorname{VO}_{2}\left(F_{(3,15)}=4.940, p=0.014\right)$, mean $\operatorname{RER}\left(F_{(3,15)}\right.$

$316=9.742, p=0.001)$, peak $\operatorname{RER}\left(F_{(3,15)}=4.616, p=0.018\right)$, and total energy expenditure $\left(F_{(3,15)}=4.338, p=0.022\right)$.

317 There were no significant effects by 'condition' for mean $\mathrm{VO}_{2}\left(F_{(1,5)}=1.198, p=0.324\right)$, peak $\mathrm{VO}_{2}\left(F_{(1,5)}=0.616, p=\right.$ $3180.468)$, mean $\operatorname{RER}\left(F_{(1,5)}=4.171, p=0.097\right)$, peak $\operatorname{RER}\left(F_{(1,5)}=3.496, p=0.120\right)$, or total energy expenditure $\left(F_{(1,5)}\right.$ $319=0.820, p=0.407)$. There were no significant 'set $\mathrm{x}$ condition' interactions for the rest periods.

320

321 Descriptive results for $\mathrm{VO}_{2}$, RER, blood lactate, aerobic, anaerobic, and total energy expenditures for each set and 322 condition in addition to where significant post hoc pairwise comparisons were present are shown in Table 2, 3, 4, and 3235 respectively.

324

325

Muscle Swelling

326

Between condition comparisons for using paired samples $t$-tests revealed no significant difference for $Q_{t}$ measurements taken prior to both conditions $\left(t_{(7)}=0.836, p=0.431\right)$ and the difference between the measures was within the SEM. Thus muscle swelling appeared to have returned close to baseline prior to commencement of the second exercise condition. Between condition comparisons for the change in $\mathrm{Q}_{\mathrm{t}}$ (i.e. difference between pre and post measures for each condition) using paired samples $t$-tests also revealed no significant difference $\left(t_{(7)}=-0.631, p=\right.$ 0.548). Further, changes exceeded the SEM suggesting a true change to have occurred. Table 6 shows the $Q_{t}$ results.

Electromyography

334 Two way repeated measures ANOVA on rank transformed data revealed no significant effects by 'set' for mean RMS amplitude $\left(F_{(3,18)}=0.304, p=0.822\right)$, peak RMS amplitude $\left(F_{(3,18)}=0.070, p=0.975\right)$, or iEMG $\left(F_{(3,18)}=0.288, p=\right.$ 
337

340

341

342

$\operatorname{amplitude}\left(F_{(1,6)}=0.475, p=0.516\right)$, or iEMG $\left(F_{(1,6)}=0.113, p=0.749\right)$. There were also no significant 'set $\mathrm{x}$ condition' interactions for mean RMS amplitude $\left(F_{(3,18)}=1.104, p=0.373\right)$, peak RMS amplitude $\left(F_{(3,18)}=0.752, p=0.535\right)$, or $\operatorname{iEMG~}\left(F_{(3,18)}=0.936, p=0.444\right)$. Figure 1 shows electromyography results within and between conditions.

\section{Perceptual Responses}

Two way repeated measures ANOVA revealed significant effects by 'set' for both perceived effort $\left(F_{(3,21)}=12.831, p\right.$ $<0.001)$, and discomfort $\left(F_{(3,21)}=18.945, p<0.001\right)$. Perceived effort significantly differed between set 1 and set 4 $(p=0.008)$, set 2 and set $3(p=0.048)$, and set 2 and set $4(p=0.017)$. Perceived discomfort significantly differed between set 1 and set $2(p=0.009)$, set 1 and set $3(p=0.003)$, set 1 and set $4(p=0.026)$, and set 2 and set $3(p=$ 0.007). There were no significant effects by 'condition' for perceived effort $\left(F_{(1,7)}=0.359, p=0.568\right)$, and discomfort $\left(F_{(1,7)}=0.281, p=0.613\right)$. There were also no significant 'set $\mathrm{x}$ condition' interactions for perceived effort $\left(F_{(3,21)}=\right.$ $0.443, p=0.725)$, and discomfort $\left(F_{(3,21)}=0.763, p=0.527\right)$. Figure 2 shows effort and discomfort results.

\section{$\underline{\text { Discussion }}$}

The aim of the present study was to examine the effects of exercise modality upon acute physiological responses when effort and duration are matched. Participants performed effort and duration matched leg press and recumbent cycle ergometry and $\mathrm{VO}_{2}$, RER, blood lactate, energy expenditure, muscle swelling, and electromyography responses were examined. Overall results indicated that, for the physiological variables examined, responses to resistance training or 'cardio' exercise modalities are similar when effort and duration are matched, supporting previous speculation (Fisher and Steele, 2014). This has been reported previously for low effort, duration matched exercise approaches (VilacaAlves et al., 2016; Kuznetsov et al., 2011) However, our study would appear to be the first to examine ecologically valid high intensity of effort exercise.

It is typically thought that a high degree of whole body $\mathrm{VO}_{2} \max$ is required in order to stimulate improvements in cardiorespiratory fitness (Astrand et al., 2003). Although this is largely unclear (Midgley et al., 2006), and the $\mathrm{VO}_{2}$ of any particular exercise bout is primarily dependent upon the muscle mass utilised during the exercise (Astrand et al., 2003; Stromme et al., 1977). Prior studies examining the $\mathrm{VO}_{2}$ responses to resistance training have in general reported it as less than $50 \%$ of whole body $\mathrm{VO}_{2} \max$ (Beckham and Earnest, 2000; Bloomer, 2005; Collins et al., 1991; Dudley, 
365 1988; Hurley et al., 1984; Phillips and Ziuratis, 2004; Phillips and Ziuratis, 2003) and as such it has been suggested 366 that it represents a poor stimulus for improving cardiorespiratory fitness (Jung, 2003). However, there are issues with 367 using comparisons of $\mathrm{VO}_{2}$ relative to whole body $\mathrm{VO}_{2}$ max for exercises involving less muscle mass than that used in

368

370

371

372

373

374

375

376

377

378

379

380

381

382

383

384

385

386

387

388

389

390

391

392

whole body testing (Steele et al., 2012). $\mathrm{VO}_{2}$ increases in a roughly linear fashion with traditional progressive 'cardio' exercise as intensity of effort increases, and indeed, with resistance training modalities there is a disproportionate increase in $\mathrm{VO}_{2}$ cost when exercise is performed to momentary failure compared with when it is stopped prior to failure (Scott and Reis, 2016; Scott and Earnest, 2011). Even with enhanced oxygen delivery, during maximal exercise it would appear that local $\mathrm{VO}_{2}$ of the active musculature is maximal in both resistance training modes (knee extension; Barden et al, 2007) as well as 'cardio' exercise modes (cycling; Calbet et al., 2006). The results of this study would appear to support this concept. There was a slightly greater mean $\mathrm{VO}_{2}$ in the recumbent cycle ergometer condition, albeit not significantly different to that during the leg press condition. The fact that this was not significantly different may be the result of a type II statistical error considering the small sample size of the present study. However, it may also be due to the fact that there is continuous concentric muscle actions during recumbent cycling as each leg alternates with each pedal stroke, whereas with the leg press $\sim 60 \%$ of the duration for each repetition was spent under eccentric muscle action. Thus, as concentric muscle actions typically elicit higher $\mathrm{VO}_{2}$ responses compared to eccentric muscle actions (Asmussen, 1953), this is unsurprising. However, we did not find any significant differences between conditions and further, peak $\mathrm{VO}_{2}$ was more similar between the two conditions. Thus, both resistance training and 'cardio' exercise modalities when performed in an effort and duration matched manner produce largely similar $\mathrm{VO}_{2}$ responses and thus may offer a similar stimulus for improvements in cardiorespiratory fitness (Steele et al., 2012).

Further, there were similar responses in terms of blood lactate. It has been suggested that accumulation of blood lactate when exercise is performed above the lactate threshold may act as a stimulus for improvement of lactate removal mechanisms (Dalleck et al., 2010; Enoksen et al., 2011), such as an up-regulation of monocarboxylate transporters (Dubochaud et al., 2000). There is a lack of research examining lactate threshold changes in response to resistance training and so far contrasting findings (Bishop et al., 1999; Marcinik et al., 1991). However, high intensity of effort interval based exercise using 'cardio' modalities have been shown to improve lactate threshold (Dalleck et al., 2010; Enoksen et al., 2011; Esfarjani et al., 2007). The similar blood lactate response between conditions in the present study suggests resistance training may also offer a similar stimulus to improve lactate removal mechanisms. Indeed the 
393 blood lactate levels reported here are similar to that produced by other 'high intensity interval training' approaches

394 (Emberts et al., 2013) as well as those reported in other studies of high effort resistance training (Hurley et al., 1984;

395 Charro et al., 2010; Denton and Cronin, 2006; Gentil et al., 2006; Tesch et al., 1986).

396

397

Aerobic, anaerobic, and total energy expenditures were also similar between both conditions. In other investigation of work and duration matched running and cycling, despite slight differences in $\mathrm{VO}_{2}$ as seen here, there were also similar energy costs (Scott et al., 2006). This is also the case with different work matched resistance training approaches (Scott, 2006; Aniceto et al., 2013). There were no significant between condition differences for either aerobic or anaerobic energy expenditures, although it did appear that anaerobic energy expenditure during the exercise periods exceeded aerobic energy expenditure for the leg press conditions, and this was reversed in the recumbent cycle ergometer condition. Further, aerobic energy costs remained similar across sets between conditions, yet blood lactate, and thus anaerobic energy costs, appeared to increase across sets for both conditions presumably as a result of cumulative fatigue and/or adjustment of load/resistance resulting in the later sets having a closer proximity to failure. This also likely influenced total energy costs across sets which increased. Indeed, fatiguing exercise resulting in failure appears to result in greater anaerobic and total energy costs compared with non-fatiguing exercise ending prior to failure (Scott and Earnest, 2011). Total energy expenditure was higher for rest periods as compared with exercise as has been shown for brief, intermittent higher intensity of effort exercise in a range of modalities (Scott and Reis, 2016; Scott and Earnest, 2011; Scott, 2006; Scott et al., 2006). However, rate of energy expenditure was higher during exercise $\left(\sim 17 \mathrm{Kcal} . \mathrm{min}^{-1}\right)$ compared with during rest $\left(\sim 9 \mathrm{Kcal} . \mathrm{min}^{-1}\right)$. Although our RER data is unclear as to substrate use during the conditions, and was likely influenced by hyperventilation due to the high effort nature of the exercise, the similar total energy expenditures of both modalities suggests also that both may also offer similar benefits in terms

414 of body mass loss efforts. Thus effort and duration of exercise may be the more influential moderators of this and 415 indeed other work suggests resistance and aerobic training appear to offer similar benefits in terms of body mass loss 416 (Villareal et al., 2017).

418 In addition to the potentially similar stimulus and benefits to cardiorespiratory fitness (Steele et al., 2012; Ozaki et al., 419 2013a), the present results also appear to support a similar acute stimulus for strength and hypertrophic adaptations.

420 It is typically thought that mechanical tension from high external loads is a primary stimulus for strength and 
421 hypertrophic adaptation (Schoenfeld, 2010). However, accumulation of metabolites such as lactate may result in so

422 called 'metabolic stress' which may also impact on factors such as cellular swelling and motor unit recruitment to

423 potentially produce adaptations even without high mechanical tension from external loads (Counts et al., 2016; Gentil

424 et al., 2017; Schoenfeld, 2013). This has mostly been considered with respect to why low load resistance training may

425 produce similar adaptations to high load resistance training (Schoenfeld, 2013; de Freitas et al., 2017), however, it has

426 also been argued it may apply to other modalities typically performed with low external loads (i.e. 'cardio' exercise

427 modes; Ozaki et al., 2016). As already noted, blood lactate response in both conditions was similar indicating similar

428 levels of metabolite accumulation, and subsequently, similar changes in $\mathrm{Q}_{\mathrm{t}}$ occurred indicating similar degrees of

429 muscular swelling. Although prior studies have reported that both 'cardio' exercise and resistance training performed

430 to high intensities of effort can induce increases in muscle water content and produce acute muscular swelling (Ozaki

431 et al., 2013b; Giessing et al., 2016; Ribiero et al., 2014; Loenneke et al., 2016; Mora-Rodriguez et al., 2016), this

432 appears to be the first to directly compare these responses between modalities when effort and duration matched.

433 Cellular swelling has also been argued to be a trigger associated with the proliferation of satellite cells and thus a

434 contributor to the hypertrophic response to exercise (Schoenfeld, 2013; de Freitas et al., 2017). In fact, other recent

435 work (Nederveen et al., 2015) comparing high effort resistance training (leg press and knee extension using 95\%10RM

436 for 2 sets of 10 repetitions and a final set to momentary failure) and 'high intensity interval training' using a 'cardio'

437 modality (cycling for 10 sets of 60 seconds at $90-95 \%$ of $\mathrm{VO}_{2}$ peak with 60 seconds recovery at $50 \mathrm{~W}$ between sets),

438 has reported that satellite cell responses in both of these modes were largely similar and higher than continuous

439 moderate effort cycling (30 minutes at 55-60\% of $\mathrm{VO}_{2}$ peak) As such, both resistance training and 'cardio' exercise

440 modalities may offer a similar stimulus for hypertrophic adaptations when performed in an effort matched manner in

441 a similar way to high and low load resistance training (Morton et al., 2016).

442

443 As noted, strength may be optimised through training using high external loads (Schoenfeld et al., 2017). However,

444 this is thought to be primarily due to specificity in motor learning and mostly occurs when strength testing closely

445 reflects the training performed (Fisher et al., 2017a; Dankel et al., 2017; Mattocks et al., 2017). When training and

446 testing are dissimilar (e.g. dynamic training performed but isometric testing conducted) both high and low external

447 loads produce similar changes in strength (Fisher et al., 2017b). This is thought to be due to Henneman's size principle,

448 and recent modelling studies suggest that motor unit recruitment should be similar between muscular actions when 
449

450

451

452

453

454

455

456

457

458

459

460

461

462

463

464

465

466

467

468

469

470

471

472

473

474

475

476

they are performed to a near maximal effort (Potvin and Fuglevand, 2017). Motor unit recruitment patterns are difficult to discern specifically from amplitude based surface EMG analyses (Fisher et al., 2017a; Vigotsky et al., 2017; Enoka and Duchateau, 2015). Indeed if tasks being compared differ considerably in effort and/or durations motor unit recruitment patterns may differ (e.g. synchronous vs sequential) such that, even though similar numbers of total motor units are recruited, EMG amplitudes may differ (Fisher et al., 2017a; Vigotsky et al., 2017 ). However, in the present study attempts were made to approximately match the efforts and durations of each exercise condition. As such, amplitude based EMG analyses were compared between conditions to give an indication of motor unit recruitment and all appeared to be similar between conditions. These results, in agreement with others (Kuznetsov et al., 2011) suggest that, when effort and duration matched, both resistance training and aerobic exercise modalities using similar muscle groups likely result in similar motor unit recruitment despite differences in external loads.

The exercise conditions in this study were designed with an attempt to maximise perceived effort per set and match it between conditions. However, our data suggested that on average perceived effort was high, but not maximal. Typically it increased across sets presumably either as a function of accumulated fatigue, and/or adjustments made to load/resistance, resulting in later sets being performed with closer proximity to failure. However, there were no differences between conditions suggesting that efforts were successfully matched between both the leg press and recumbent cycle ergometer. Discomfort scales were also used in order to get participants to disentangle their perceptions of effort from associated physical discomfort as it is common for people to anchor one upon the other with traditional rating of perceived exertion scales (Steele et al., 2017c). Discomfort also increased across sets, yet without differences between conditions. Discomfort has been suggested to be more closely related to afferent feedback (Marcora, 2009) and the similar increases seen here between both conditions may be a result of similar stimulation of group III and IV fibres providing afferent feedback about the metabolic and mechanical conditions induced by the exercise. Indeed as noted, the physiological responses examined were largely similar between conditions including blood lactate increases, muscle swelling, and EMG amplitudes. In studies of resistance training where effort has been matched yet other variables manipulated, for example load or the use of advanced training techniques, discomfort can differ (Fisher et al., 2017b; 2017c). Yet these results suggest that when effort and duration are matched the discomfort experienced is also similar between exercise modalities utilising similar muscle groups. 
477 The results of this study suggest that, at least when considering the variables measured (i.e. $\mathrm{VO}_{2}$, $\mathrm{RER}^{\mathrm{R}}$, blood lactate,

478 energy expenditure, muscle swelling, and electromyography), the physiological stimulus provided by both resistance

479 training (leg press), and 'cardio' exercise (recumbent cycle ergometry), when effort and duration matched may be

480 largely similar. As such, similar chronic physiological adaptations may possibly occur from either modality when

481 performed with a similar effort and duration. However, there is currently a lack of research examining the chronic

482 adaptations to appropriately matched resistance training and 'cardio' exercise modalities. Studies directly comparing

resistance training and 'cardio' training modalities upon these chronic adaptations contrast in their findings (Farup et

Wilkinson et al., 2008) and this may be due to the fact that effort and duration have not been matched. Resistance

training is typically performed with a relatively high effort (though not always) and with varying durations, and

'cardio' exercise is typically performed with a low to moderate effort and high durations. Yet, a recent study has

suggested that, when performed in an effort and duration matched manner, 8 weeks additional resistance training mode (squats and deadlifts), or 'cardio' exercise mode (upright cycle ergometry) 'high intensity interval training' produces athletes (Androulakis-Korakakis et al., 2017). Considering, the highly trained nature of the population in that study, similar results might occur in an untrained population. Indeed, another study examining 12 weeks of effort and resistance training including biceps curls, knee extension, shoulder press, and upright rows) also showed that a range of outcomes were similar in insulin resistance women (Álvarez et al., 2017). Future work should thus look to further examine effort and duration matched interventions, such as that used here, upon chronic physiological adaptations in cardiorespiratory fitness, strength, and hypertrophy across a range of populations. Such work should also be careful to avoid the confounding influence of specificity of training and testing and use outcomes that will not bias towards $\mathrm{VO}_{2}$ max using an upright cycle ergometer or treadmill, and testing for strength using isometric knee extension.

502 The limitations of the present study should be acknowledged. The sample size was relatively small for this study. Although we utilised a within session randomised crossover design in order to increase the statistical power of our comparisons, it may be that some of the variables examined were not found to be statistically significantly different 
505 as a result of a type II error. Although, it could contrastingly be argued that, as a wide range of different physiological 506 responses were examined, it might have been expected that the chances of a type I error might have been increased.

507 Future work should perhaps look to replicate our study design with a larger sample to clarify if indeed the physiological 508 responses to differing exercise modalities are similar when effort and duration matched. It should also be noted that 509 all of the variables measured were examined during and immediately after the exercise periods. Measures such as

510 hormonal concentrations or biochemical signalling pathways relevant to understanding the stimulus provided by an 511 exercise bout were not examined yet may differ dependent upon modality. However, similarly to the responses 512 examined here, previous research has generally not controlled appropriately for both effort and duration when 513 comparing signalling responses across modalities (Wilkinson et al., 2008). As such, future work may also look to 514 examine other acute responses, during, and for longer periods after, the exercise bouts (i.e. up to 24-48 hours post 515 exercise).

516

\section{Conclusions}

518 The present study shows that, when both effort and duration are matched, resistance training (leg press) and 'cardio' 519 exercise (recumbent cycle ergometry) may produce largely similar responses in $\mathrm{VO}_{2}$, RER, blood lactate, energy 520 expenditure, muscle swelling, and electromyography. It therefore seems reasonable to suggest that both may offer a 521 similar stimulus to produce chronic physiological adaptations in outcomes such as cardiorespiratory fitness, strength, 522 and hypertrophy. Although there is limited research comparing the chronic adaptations from such matched exercise 523 modalities, the implications of such findings might be significant. If modality has little impact upon changes in 524 physiological fitness outcomes known to be strong predictors of health and longevity then there may be potential for 525 public health messages about physical activity and exercise to be widened to increase participation. Persons may be 526 able to select their exercise mode based upon personal preferences and/or circumstances, and instead focus upon a key 527 message to engage in such activities with a high intensity of effort. Future work should look to both replicate the study 528 conducted here with respect to the same, and additional physiological measures, and rigorously test the comparative 529 efficacy of effort and duration matched exercise of differing modalities with respect to chronic improvements in 530 physiological fitness.

531

\section{References}


533

534

535

536

537

538

539

540

541

542

543

544

545

546

547

548

549

550

551

552

553

554

555

556

557

558

559

560
1. Álvarez, C., Ramirez-Campillo, R., Ramirez-Vélez, R., and Izquierdo, M., 2017. Effects and prevalence of nonresponders after 12 weeks of high-intensity interval or resistance training in women with insulin resistance: a randomized trial. J. Appl. Physiol. 122: 985-986

2. Androulakis-Korakkakis, P., Langdown, L., Lewis, A., Fisher, J., Gentil, P., Paoli, A., and Steele, J. 2017. The effects of exercise modality during additional 'high-intensity interval training' upon aerobic fitness and strength in powerlifting and strongman athletes. J. Strength. Cond. Res. Epub ahead of print. DOI: 10.1519/JSC.0000000000001809

3. Aniceto, R.R., Ritti-Dias, R.M., Scott, C.B., de Lima, F.F.M., dos Prazeres, T.M.P., and do Prado, W.L. 2013. Acute effects of different weight training methods on energy expenditure in trained men. Revista. Braileira. de Medicina. do Esporte. 19: 181-185

4. Asmussen, E. 1953. Positive and negative muscular work. Acta. Physiol. Scand. 28: 364-382

5. Astrand, P.O., Rodahl, K., Dahl, H.A., and Stromme, S.B. 2003. Textbook of work physiology: Physiological bases of exercise. Human Kinetics, Champaign, NL

6. Atherton, P.J., Babraj, J., Smith, K., Singh, J., Rennie, M.J., and Wackerhage, H. 2005. Selective activation of AMPK-PGC-1alpha or PKB-TSC2-mTOR signalling can explain specific adaptive responses to endurance or resistance training-like electrical muscle stimulation. FASEB. J. 19: 786-788

7. Barden, J., Lawrenson, L., Poole, J.G., Kim, J., Wray, D.W., Bailey, D.M., and Richardson, R.S. 2007. Limitations to vasodilatory capacity and VO2 max in trained human skeletal muscle. Am. J. Physiol. Heart. Circ. Physiol. 292: H2491-2497

8. Beckham, S.G., and Earnest, C.P. 2000. Metabolic cost of free weight circuit weight training. J. Sports. Med. Phys. Fitness. 40: 118-125

9. Biddle, S.J.H., and Batterham, A.M. 2015. High-intensity interval exercise training for public health: a big HIT or shall we HIT it on the head? Int. J. Behav. Nutr. Phys. Act. 12: 95

10. Bishop, D., Jenkins, D.G., Mackinnon, L.T., McEniery, M., and Carey, M.F. 1999. The effects of strength training on endurance performance and muscle characteristics. Med. Sci. Sports. Exerc. 31: 886891

11. Bloomer, R.J. 2005. Energy cost of moderate-duration resistance and aerobic exercise. J. Strength. Cond. Res. 19: $878-882$ 
561

562

563

564

565

566

567

568

569

570

571

572

573

574

575

576

577

578

579

580

581

582

583

584

585

586

587
12. Buckner, S.L., Loenneke, J.P., and Loprinzi, P.D. 2015. Lower extremity strength, systemic inflammation and all-cause mortality: Application to the "fat but fit" paradigm using cross-sectional and longitudinal designs. Physiol. Behav. 149: 199-202

13. Byberg, L., Melhus, H., Gedeborg, R., Sundstrom, J., Ahlbom, A., Zethelius, B., Berglund, L.G., Wolk, A., and Michaelsson, K. 2009. Total mortality after changes in leisure time physical activity in 50 year old men: 35 year follow up of population based cohort. Br. J. Sports. Med. 43: 482

14. Calbet, J.A., Lundby, C., Sander, M., Robach, P., Saltin, B., and Boushel, R. 2006. Effects of ATPinduced leg vasodilation on $\mathrm{VO} 2$ peak and leg $\mathrm{O} 2$ extraction during maximal exercise in humans. Am. J. Physiol. Regul. Integr. Comp. Physiol. 291: R447-453

15. Charro, M.A., Aoki, M.S., Coutts, A.J., Araujo, R.C., and Bacurau, R.F. 2010. Hormonal, metabolic and perceptual responses to different resistance training systems. J. Sports. Med. Phys. Fitness. 50: 229-234

16. Collins, M.A., Cureton, K.J., Hill, D.W., and Ray, C.A. 1991. Relationship of heart rate to oxygen uptake during weight lifting exercise. Med. Sci. Sports. Exerc. 23: 636-640

17. Counts, B.R., Buckner, S.L., Dankel, S.J., Jessee, M.B., Mattocks, K.T., Mouser, J.G., Laurentino, G.C., and Loenneke, J.P. 2016. The acute and chronic effects of "NO LOAD" resistance training. Physiol. Behav. 164: 345-352

18. Dalleck, L., Bushman, T.T., Crain, R.D., Gajda, M.M., Koger, E.M., and Derksen, L.A. 2010. Doseresponse relationship between interval training frequency and magnitude of improvement in lactate threshold. Int. J. Sports. Med. 31: 567-571

19. Dankel, S.J., Counts, B.R., Barnett, B.E., Buckner, S.L., Abe, T., and Loenneke, J.P. 2017. Muscle adaptations following 21 consecutive days of strength test familiarization compared with traditional training. Muscle. Nerve. 56: 307-314

20. de Freitas, M.C., Gerosa-Neto, J., Zanchi, N.E., Lira, F.S., and Rossi, F.E., 2017. Role of metabolic stress for enhancing muscle adaptations: Practical applications. World. J Methodol. 7: 46-54

21. de Oliviera, M.F., Caputo, F., Corvino, R.B., and Denadai, B.S. 2016. Short-term low-intensity blood flow restricted interval training improves both aerobic fitness and muscle strength. Scand. J. Med. Sci. Sports. 26: 1017-1025 
588

589

590

591

592

593

594

595

596

597

598

599

600

601

602

603

604

605

606

607

608

609

610

611

612

613

614

22. Denton, J., and Cronin, J.B. 2006. Kinematic, kinetic, and blood lactate profiles of continuous and intraset rest loading schemes. J. Strength. Cond. Res. 20: 528-534

23. Dubochaud, H., Butterfield, G.E., Wolfel, E.E., Bergman, B.C., and Brooks, G.A. 2000. Endurance training, expression, and physiology of LDH, MCT1, and MCT4 in human skeletal muscle. Am. J. Physiol. Endocrinol. Metab. 278: E571-579

24. Dudley. G/A/ 1988. Metabolic consequences of resistive-type exercise. Med. Sci. Sports. Exerc. 20: S158-161

25. Emberts, T., Porcari, J., Doberstein, S., Steffen, J., and Foster, C. 2013. Exercise intensity and energy expenditure of a tabata workout. J. Sport. Sci. Med. 12: 612-613

26. Enoka, R.M., and Duchateau, J. 2015. Inappropriate interpretation of surface EMG signals and muscle fiber characteristics impedes understanding of the control of neuromuscular function. J. Appl. Physiol. 119: $1516-1518$

27. Enoksen, E., Shalfawi, S.A., Tonnessen, E. 2011. The effect of high- vs. Low-intensity training on aerobic capacity in well-trained male middle-distance runners. J. Strength. Cond. Res. 25: 812-818

28. Ericson, M.O., Nisell, R., Arborelius, U.P., and Ekholm, J. 1985. Muscular activity during ergometer cycling. Scand. J. Rehabil. Med. 17: 53-61

29. Esfarjani, F., and Laursen, P.B. 2007. Manipulating high-intensity interval training: effects on VO2max, the lactate threshold and 3000m running performance in moderately trained males. J. Sci. Med. Sport. 10: $27-35$

30. Farup, J., Kjolhede, T., Sorenson, H., Dalgas, U., Moller, A.B., Vestergaard, P.F., Ringgaard, S., BojsenMoller, J., and Vissing, K. 2012. Muscle morphological and strength adaptations to endurance vs. resistance training. J. Strength. Cond. Res. 26: 398-407

31. Fisher, J., and Steele, J. 2014. Questioning the Resistance/Aerobic Training Dichotomy; A commentary on physiological adaptations determine by effort rather than exercise modality. J. Hum. Kinet. 44: 137142

32. Fisher, J., Steele, J., and Smith, D. 2017a. High- and low-load resistance training: Interpretation and practical application of current research findings. Sports. Med. 47: 393-400 
615

616

617

618

619

620

621

622

623

624

625

626

627

628

629

630

631

632

633

634

635

636

637

638

639

640

641
33. Fisher, J.P., Farrow, J., and Steele, J. 2017c. Acute fatigue, and perceptual responses to resistance exercise. Muscle. Nerve. 56: E141-146

34. Fisher, J.P., Ironside, M., and Steele, J. 2017b. Heavier and lighter load resistance training to momentary failure produce similar increases in strength with differing degrees of discomfort. Muscle. Nerve. 56: $797-803$

35. Gentil, P., Bottaro, M., Noll, M., Werner, S., Vasconcelos, J.C., Seffrin, A., and Campos, M.H. 2017. Muscle activation during resistance training with no external load - effects of training status, movement velocity, dominance, and visual feedback. Physiol. Behav. 179: 148-152

36. Gentil, P., Oliveira, E., and Bottaro, M. 2006. Time under tension and blood lactate response during four different resistance training methods. J. Physiol. Anthropol. 25: 339-344

37. Giessing, J., Fisher, J., Steele, J., Rothe, F., Raubold, K., and Eichmann, B. 2016. The effects of low volume resistance training with and without advanced techniques in trained participants. J. Sports. Med. Physical. Fitness. 56: 249-258

38. Goldberg, L., Elliot, D.L., and Kuehl, K.S. 1994. A comparison of the cardiovascular effects of running and weight training. J. Strength. Cond. Res. 8: 219-224

39. Haskell, W.L., Lee, I., Pate, R.R., Powell, K.E., Blair, S.N., Franklin, B.A., Macera, C.A., Heath, G.W., Thompson, P.D., and Bauman, A. 2007. Physical activity and public health: Updated recommendation for adults from the American College of Sports Medicine and the American Heart Association. Med. Sci. Sports. Exerc. 39: 1423- 1434

40. Hepple, R.T., Mackinnon, S.L., Goodman, J.M., Thomas, S.G., and Plyley, M.J. 1997. Resistance and aerobic training in older men: effects on VO2peak and the capillary supply to skeletal muscle. J. Appl. Physiol. 82: 1305-1310

41. Hurley, B.F., Seals, D.R., Ehsani, A.A., Cartier, L.J., Dalsky, G.P., Hagberg, J.M., and Holloszy, J.O. 1984. Effects of high-intensity strength training on cardiovascular function. Med. Sci. Sports. Exerc. 16: $483-488$

42. Jubrias, S.A., Esselman, P.C., Price, L.B., Cress, M.E., and Conley, K.E. 2001. Large energetic adaptations of elderly muscle to resistance and endurance training. J. Appl. Physiol. 90: 1663-1670 
642

643

644

645

646

647

648

649

650

651

652

653

654

655

656

657

658

659

660

661

662

663

664

665

666

667

668

43. Jung, A.P. 2003. The impact of resistance training on distance running performance. Sports. Med. 33: 539-552

44. Kodama, S., Saito, K., Tanaka, S., Maki, M., Yachi, Y., Asumi, M., Sugawara, A., Totsuka, K., Shimano, H., Ohashi, Y., Yamada, N., and Sone, H. 2009. Cardiorespiratory fitness as a quantitative predictor of all-cause mortality and cardiovascular events in health men and women: a meta-analysis. JAMA. 301: 2024-2035

45. Konopka, A.R., Harber, M.P. 2014. Skeletal muscle hypertrophy after aerobic exercise training. Exerc. Sport. Sci. Rev. 42: 53-61

46. Kuznetsov, S.Y., Popov, D.V., Borovik, A.S., and Vinogradova, O.L. 2011. Wavelet analysis of the m. vastus lateralis surface electromyography activity in incremental tests until exhaustion using bicycle and knee extension exercises. Hum. Physiol. 37: 629

47. Lee, D.C., Sui, X., Ortega, F.B., Kim, Y.S., Church, T.S., Winett, R.A., Ekelund, U., Katzmarzyk, P.T., and Blair, S.N. 2011. Comparisons of leisure-time physical activity and cardiorespiratory fitness as predictors of all-cause mortality in men and women. Br. J. Sports. Med. 45: 504-510

48. Lee, I., Skerrett, P.J. 2001. Physical activity and all-cause mortality: what is the dose-response relation? Med. Sci. Sports. Exerc. 33: S459-S471

49. Leong, D.P., Teo, K.K., Rangarajan, S., Lopez-Jaramillo, P., Avezum, A. Jr., Orlandini, A., Seron, P., Ahmed, S.H., Rosengren, A., Kelishadi, R., Rahman, O., Swaminathan, S., Iqbal, R., Gupta, R., Lear, S.A., Oguz, A., Yusoff, K., Zatonska, K., Chifamba, J., Igumbor, E., Mohan, V., Anjana, R.M., Gu, H., Li, W., Yusuf, S., 2015. Prognostic value of grip strength: findings from the Prospective Urban Rural Epidemiology (PURE) study. Lancet. 386: 266-273

50. Loenneke, J.P., Kim, D., Fahs, C.A., Thiebaud, R.S, Abe, T., Larson, R.D., Bemben, D.A., and Bemben, M.G. 2016. The influence of exercise load with and without different levels of blood flow restriction on acute changes in muscle thickness and lactate. Clin. Physiol. Funct. Imaging.37: 734-740

51. Loprinzi, P.D. 2015a. Dose-response association of moderate to vigorous physical activity with cardiovascular biomarkers and all-cause mortality: considerations by individual sports, exercise and recreational physical activities. Prev. Med. 81: 73-77 
669

670

671

672

673

674

675

676

677

678

679

680

681

682

683

684

685

686

687

688

689

690

691

692

693

694

695

52. Loprinzi, P.D. 2015b. Cardiorespiratory capacity and leukocyte telomere length among adults in the United States. Am. J. Epidemiol. 182: 198-201

53. Loprinzi, P.D. 2016. Lower extremity muscular strength, sedentary behaviour, and mortality. Age. 38: 32

54. Loprinzi, P.D., and Loenneke, J.P. 2016. Lower extremity muscular strength and leukocyte telomere length: Implications of muscular strength in attenuating age-related chronic disease. J. Phys. Act. Health. 13: $454-457$

55. Lundberg, T.R., Fernandez-Gonzalo, R., Gustafsson, R.T., and Tesch, P.A. 2013. Aerobic exercise does not compromise muscle hypertrophy response to short-term resistance training. J. Appl. Physiol. 114: $81-89$

56. Marcinik, E.J., Potts, J., Schlabach, G., Will, S., Dawson, P., and Hurley, B.F. 1991. Effects of strength training on lactate threshold and endurance performance. Med. Sci. Sports. Exerc. 23: 739-743

57. Marcora, S. 2009. Perception of effort during exercise is independent of afferent feedback from skeletal muscles, heart, and lungs. J. Appl. Physiol. 106: 2060-2062

58. Marsh, A.P., and Martin, P.E. 1995. The relationship between cadence and lower extremity EMG in cyclists and noncyclists. Med. Sci. Sports. Exerc. 27: 217-225

59. Mattocks, K.T., Buckner, S.L., Jessee, M.B., Dankel, S.J., Mouser, J.G., and Loenneke, J.P. 2017. Practicing the test produces strength equivalent to higher volume training. Med. Sci. Sports. Exerc. 49: 1945-1954

60. Maughan, R., Leiper, J., and Greaves, M. 2011. Haemotology. In: Kinanthropometry and Exercise Physiology Laboratory Manual: Tests, Procedures and Data, 2nd ed, ed. Eston R, Reilly R. Routledge, Abingdon, Oxon

61. Messier, S.P., and Dill, M.E. 1985. Alterations in strength and maximal oxygen uptake consequent to nautilus circuit weight training. Res. Q. Exerc. Sport. 56: 345-351

62. Midgley, A.W., McNaughton, L.R., and Wilkinson, M. 2006. Is there an optimal training intensity for enhancing the maximal oxygen uptake of distance runners?: empirical research findings, current opinions, physiological rationale and practical recommendations. Sports. Med. 36: 117-132 
696

697

698

699

700

701

702

703

704

705

706

707

708

709

710

711

712

713

714

715

716

717

718

719

720

721

722

723
63. Mora-Rodriguez, R., Sanchez-Roncero, A., Fernandez-Elias, V.E., Guadalupe-Grau, A., Ortega, J.F., Dela, F., and Helge, J.W. 2016. Aerobic exercise training increases muscle water content in obese middle-age men. Med. Sci. Sports. Exerc. 48: 822-828

64. Morton, R.W., Oikawa, S.Y., Wavell, C.G., Mazara, N., McGlory, C., Quadrilatero, J., Baechler, B.L., Baker, S.K., and Phillips, S.M. 2016. Neither load nor systemic hormones determine resistance trainingmediated hypertrophy or strength gains in resistance-trained young men. J. Appl. Physiol. 121: 129-138

65. Nader, G.A. 2006. Concurrent strength and endurance training: from molecules to man. Med. Sci. Sports. Exerc. 38: 1965-1970

66. Nederveen, J.P., Joanisse, S., Ségun, C.M.L., Bell, K.E., Baker, S.K. Phillips, S.M., and Pairse, G>, 2015. The effect of exercise mode on the acute response of satellite cells in old men. Acta. Physiol. 215: $177-190$

67. Newman, A.B., Kupelian, V., Visser, M., Simonsick, E.M., Goodpaster, B.H., Kritchevsky, S.B., Tylavsky, F.A., Rubin, S.M., and Harris, T.B. 2006. Strength, but not muscle mass, is associated with mortality in the health, aging and body composition study cohort. J. Gerontol. A. BiolSci. Med. Sci. 61: $72-77$

68. Noble, E.B., Pilarski, J.M., Vora, H.K., Zuniga, J.M., and Malek, M.H. 2017. Log-transformed EMG amplitude-power output relationship: Single-leg knee-extensor versus single-leg cycle ergometry. J. Strength. Cond. Res. Epub ahead of print. DOI: 10.1519/JSC.0000000000001950

69. Nocon, M., Hiemann, T., Muller-Riemenschneider, F., Thalau, F., Roll, S., and Willich, S.N. 2008. Association of physical activity with all-cause and cardiovascular mortality: a systematic review and meta-analysis. Eur. J. Cardiovasc. Prev. Rehabil. 15: 239-246

70. Ozaki, H., Loenneke, J.P., Buckner, S.L., and Abe, T. 2016. Muscle growth across a variety of exercise modalities and intensities: Contributions of mechanical and metabolic stimuli. Med. Hypotheses. 88: 2226

71. Ozaki, H., Loenneke, J.P., Thiebaud, R.S., and Abe, T. 2013a. Resistance training induced increase in $\mathrm{VO}_{2} \mathrm{max}$ in young and older subjects. Eur. Rev. Aging. Phys. Act. 10: 107-116

72. Ozaki, H., Loenneke, J.P., Thiebaud, R.S., and Abe, T. 2015. Cycle training induces muscle hypertrophy and strength gain: strategies and mechanisms (Review). Acta. Phsiol. Hung. 102: 1-22 
724

725

726

727

728

729

730

731

732

733

734

735

736

737

738

739

740

741

742

743

744

745

746

747

748

749

750
73. Ozaki, H., Loenneke, J.P., Thiebaud, R.S., Stager, J.M., and Abe, T. 2013b. Possibility of leg muscle hypertrophy by ambulation in older adults: a brief review. Clin. Interv. Aging. 8: 369-375

74. Paffenbarger, R.S. Jr., Hyde, R.T., Wing, A.L., and Hsieh, C.C. 1986. Physical activity, all-cause mortality, and longevity of college alumni. N. Engl. J. Med. 314: 605-613

75. Phillips, S., and Winett, R. 2010. Uncomplicated resistance training and health-related outcomes: evidence for a public health mandate. Curr. Sports. Med. Rep. 9: 208-213

76. Phillips, W.T., and Ziuratis, J.R. 2003. Energy cost of the ACSM single-set resistance training protocol. J. Strength. Cond. Res. 17: 350-355

77. Phillips, W.T., and Ziuratis, J.R. 2004. Energy cost of single-set resistance training in older adults. J. Strength. Cond. Res. 18: 606-609

78. Potvin, J.R., and Fuglevand, A.J. 2017. A motor unit-based model of muscle fatigue. PLoS. Comput. Biol. 13: e1005581

79. Ribiero, A.S., Avelar, A., Schoenfeld, B.J., Ritti Dias, R.M., Altimari, L.R., and Cyrino, E.S. 2014. Resistance training promotes increases in intracellular hydration in men and women. Eur. J. Sport. Sci. 14: $578-585$

80. Ruiz, J.R., Sui, X., Lobelo, F., Morrow, J.R., Jackson, J.W., Sjostrom, M., and Blair, S.N. 2008. Association between muscular strength and mortality in men: prospective cohort study. BMJ. 337: 439

81. Sawczyn, S., Mischenko, V., Moska, W., Sawczyn, M., Jagiello, M., Kuekne, T., Kostrzewa-Nowak, D., Nowak, R., and Cieszczyk, P. 2015. Strength and aerobic training in overweight females in Gdansk, Poland. Open. Med. 10: 152-162

82. Schoenfeld, B.J. 2013. Potential mechanisms for a role of metabolic stress in hypertrophic adaptations to resistance training. Sports. Med. 43: 179-194

83. Schoenfeld, B.J., Grgic, J., Ogborn, D., and Krieger, J.W. 2017. Strength and hypertrophy adaptations between low- versus high-load resistance training: A systematic review and meta-analysis. J. Strength. Cond. Res. Epub ahead of print. DOI: 10.1519/JSC.0000000000002200

84. Schoenfeld, B.J. 2010. The mechanisms of muscle hypertrophy and their application to resistance training. J. Strength. Cond. Res. 24: 2857-2872 
751

752

753

754

755

756

757

758

759

760

761

762

763

764

765

766

767

768

769

770

771

772

773

774

775

776

777
85. Scott, C., and Reis, V.M. 2016. Modelling the total energy costs of resistance exercise: A work in progress. Cent. Eur. J. Sport. Sci. Med. 14: 5-12

86. Scott, C.B. 2006. Estimating energy expenditure for brief bouts of exercise with acute recovery. Appl. Physiol. Nutr. Metab. 31: 144-149

87. Scott, C.B., and Earnest, C.P. 2011. Resistance exercise energy expenditure is greater with fatigues as compared to non-fatigue. J. Exerc. Physiol. 14: 1-10

88. Scott, C.B., Littlefield, N.D., Chason, J.D., Bunker, M.P., and Asselin, E.M. 2006. Difference in oxygen uptake but equivalent energy expenditure between a brief bout of cycling and running. Nutr. Metab. 3: 1

89. Srikanthan, P., and Karlamangla, A.S. 2014. Muscle mass index as a predictor of longevity in older adults. Am. J. Med. 127: 547-553

90. Sriknathan, P., Horwich, T.B., and Tseng, C.H. 2016. Relation of muscle mass and fat mass to cardiovascular disease mortality. Am. J. Cardiol. 117: 1355-1360

91. Steele, J. 2014. Intensity; in-ten-si-ty; noun. 1. Often used ambiguously within resistance training. 2. Is it time to drop the term altogether? Br. J. Sports. Med. 48: 1586-1588

92. Steele, J., Fisher, J., Gessing, J., and Gentil, P. 2017b. Clarity in reporting terminology and definitions of set endpoints in resistance training. Muscle. Nerve. 56: 368-374

93. Steele, J., Fisher, J., McGuff, D., Bruce-Low, S., and Smith, D. 2012. Resistance training to momentary muscular failure improves cardiovascular fitness in humans: A review of acute physiological responses and chronic physiological adaptations. J. Exerc. Physiol. 15: 53-80

94. Steele, J., Fisher, J., McKinnon, S., and McKinnon, P. 2017c. Differentiation between perceived effort and discomfort during resistance training in older adults: Reliability of trainee ratings of effort and discomfort, and reliability and validity of trainer ratings of trainee effort. J. Trainol. 6: 1-8

95. Steele, J., Fisher, J., Skivington, M., Dunn, C., Arnold, J., Tew, G., Batterham, A.M., Nunan, D., O’Driscoll, J.M., Mann, S., Beedie, C., Jobson, S., Smith, D., Vigotsky, A., Phillips, S., Estabrooks, P., and Winett, R. 2017a. A higher effort-based paradigm in physical activity and exercise for public health: making the case for greater emphasis on resistance training. BMC. Public. Health. 17: 300 
778

779

780

781

782

783

784

785

786

787

788

789

790

791

792

793

794

795

796

797

798

799

800

801

802

803

804

805

96. Strand, B.H., Cooper, R., Bergland, A., Jorgensen, L., Schirmer, H., Skirbekk, V., and Emaus, N. 2016. The association of grip strength from midlife onwards with all-cause and cause-specific mortality over 17 years of follow-up in the Tromso Study. J. Epidemiol. Community. Health. Epub ahead of print. DOI: 10.1136/jech-2015-206776

97. Stromme, S.B., Ingier, F., and Meen, M.D. 1977. Assessment of maximal aerobic power in specifically trained athletes. J. Appl. Physiol. Respir. Environ. Exerc. Physiol. 42, 833-837

98. Tesch, P.A., Colliander, E.B., and Kaiser, P. 1986. Muscle metabolism during intense, heavy-resistance exercise. Eur. J. Appl. Physiol. Occup. Physiol. 55: 362-366

99. Vigotsky, A.D., Beardsley, C., Contreras, B., Steele, J., Ogborn, D., and Phillips, S.M. 2017. Greater electromyographic responses do not imply greater motor unit recruitment and 'hypertrophic potential' cannot be inferred. J. Strength. Cond. Res. 31: e1-e4

100.Vilaca-Alves, J., Freitas, N.M., Saavedra, F.J., Scott, C.B., Reis, V.M., Simao, R., and Garrido, N. 2016. Comparison of oxygen uptake during and after the execution of resistance training exercises and exercise ergometers, matched for intensity. J. Hum. Kinet. 52: 179-187

101.Villareal, D.T., Aguirre, L., Gurney, A.B., Waters, D.L., Sinacore, D.R., Colombo, E., ArmamentoVillareal, R., and Qualls, C. 2017. Aerobic or resistance exercise, or both, in dieting obese older adults. N. Eng. J. Med. 376: 1943-1955

102.Wen, C.P., Wai, J.P., Tsai, M.K., Yang, Y.C., Cheng, T.Y., Lee, M.C., Chan, H.T., Tsao, C.K., Tsai, S.P., and Wu, X. 2011. Minimum amount of physical activity for reduced mortality and extended life expectancy: a prospective cohort study. Lancet. 378: 1244-1253

103.Wilkinson, S.B., Phillips, S.M., Atherton, P.J., Patel, R., Yarasheski, K.E., Tarnopolsky, M.A., and Rennie, M.J. 2008. Differential effects of resistance and endurance exercise in the fed state on signalling molecule phosphorylation and protein synthesis in human muscle. J. Physiol. 586: 3701-3717

\section{Figure Titles}

Figure 1. Comparison across sets, and between conditions, for mean RMS amplitude (A), peak RMS amplitude (B), and $\mathrm{iEMG}(\mathrm{C})$ - Mean (SD) 
806 Figure 2. Comparison across sets, and between conditions for perceived effort (A), and perceived discomfort (B) 807 Mean (SD) 
Table $\mathbf{1}$ (on next page)

Participant demographics 
Table 1. Participant demographics

\begin{tabular}{cc}
\hline Variable & Mean $(\mathrm{SD})$ \\
\hline Age (years) & $26(10)$ \\
Height $(\mathrm{cm})$ & $179.7(6.2)$ \\
Body $(\mathrm{kg})$ & $87.2(10.5)$ \\
Body Mass Index $\left(\mathrm{kg} \cdot \mathrm{m}^{2}\right)$ & $27.1(3.5)$ \\
Systolic blood pressure $(\mathrm{mmHg})$ & $129.6(6.7)$ \\
Diastolic blood pressure $(\mathrm{mmHg})$ & $74.2(8.3)$ \\
\hline
\end{tabular}




\section{Table 2 (on next page)}

Mean (SD) for mean and peak $\mathrm{VO}_{2}$ results for sets, rest periods, and averages 
1 Table 2. Mean (SD) for mean and peak $\mathrm{VO}_{2}$ results for sets, rest periods, and averages

\begin{tabular}{|c|c|c|c|}
\hline Variable & Period & Leg Press & Recumbent Cycle Ergometer \\
\hline \multirow{11}{*}{$\begin{array}{l}\text { Mean } \mathrm{VO}_{2} \\
\left(\mathrm{ml} \cdot \mathrm{kg} \cdot \mathrm{min}^{-1}\right)\end{array}$} & Set 1 & $18.54(6.35)$ & $26.08(8.74)$ \\
\hline & Set 2 & $18.68(5.29)$ & $26.95(7.67)$ \\
\hline & Set 3 & $18.77(5.91)$ & $28.24(8.35)$ \\
\hline & Set 4 & $19.96(7.57)$ & $28.06(8.24)$ \\
\hline & Average Sets & $19.37(6.50)$ & $27.33(7.97)$ \\
\hline & Rest 1 & $15.94(3.14)$ & $17.35(2.86)$ \\
\hline & Rest 2 & $16.15(3.52)$ & $18.41(2.73)$ \\
\hline & Rest 3 & $16.37(3.36)$ & $18.75(3.05)$ \\
\hline & Rest 4 & $16.11(2.94)$ & $17.67(2.40)$ \\
\hline & Average Rest & $16.00(3.38)$ & $17.72(2.78)$ \\
\hline & Average Whole & $17.68(4.82)$ & $22.52(5.20)$ \\
\hline \multirow{11}{*}{$\begin{array}{l}\text { Peak } \mathrm{VO}_{2} \\
\left(\mathrm{ml} . \mathrm{kg} \cdot \mathrm{min}^{-1}\right)\end{array}$} & Set 1 & $31.87(7.63)$ & $36.87(11.25)$ \\
\hline & Set 2 & $33.54(12.66)$ & $40.47(11.74)$ \\
\hline & Set 3 & $33.01(10.57)$ & $40.32(10.42)$ \\
\hline & Set 4 & $38.33(14.39)$ & $40.90(11.73)$ \\
\hline & Average Sets & $34.75(11.66)$ & $39.64(10.79)$ \\
\hline & Rest 1 & $34.37(10.90)$ & $35.40(7.80)$ \\
\hline & Rest 2 & $37.13(7.43)$ & $38.14(7.88)$ \\
\hline & Rest 3 & $30.85(14.01)$ & $39.61(9.62)$ \\
\hline & Rest 4 & $35.34(6.60)$ & $39.51(8.49)$ \\
\hline & Average Rest & $34.93(6.81)$ & $37.41(8.76)$ \\
\hline & Average Whole & $34.84(9.45)$ & $38.53(9.57)$ \\
\hline
\end{tabular}

2 


\section{Table 3 (on next page)}

Mean (SD) for mean and peak RER results for sets, rest periods, and averages 
1 Table 3. Mean (SD) for mean and peak RER results for sets, rest periods, and averages

\begin{tabular}{|c|c|c|c|}
\hline Variable & Period & Leg Press & Recumbent Cycle Ergometer \\
\hline \multirow[t]{11}{*}{ Mean RER } & Set 1 & $0.88(0.05)$ & $1.11(0.22)$ \\
\hline & Set 2 & $0.91(0.06)$ & $1.03(0.13)$ \\
\hline & Set 3 & $0.93(0.06)$ & $0.95(0,07)$ \\
\hline & Set 4 & $0.89(0.05)$ & $0.89(0.06)$ \\
\hline & Average Sets & $0.92(0.02)$ & $0.99(0.11)$ \\
\hline & Rest 1 & $1.13(0.17)$ & $1.36(0.22)$ \\
\hline & Rest 2 & $1.09(0.10)$ & $1.22(0.12)$ \\
\hline & Rest 3 & $1.09(0.08)$ & $1.16(0.08)$ \\
\hline & Rest 4 & $1.07(0.07)$ & $1.12(0.10)$ \\
\hline & Average Rest & $1.10(0.10)$ & $1.22(0.13)$ \\
\hline & Average Whole & $1.01(0.06)$ & $1.11(0.12)$ \\
\hline \multirow[t]{11}{*}{ Peak RER } & Set $1^{\mathrm{a}}$ & $1.09(0.13)$ & $1.33(0.30)$ \\
\hline & Set 2 & $1.11(0.12)$ & $1.32(0.30)$ \\
\hline & Set 3 & $1.13(0.11)$ & $1.20(0.21)$ \\
\hline & Set 4 & $1.06(0.08)$ & $1.14(0.14)$ \\
\hline & Average Sets & $1.12(0.05)$ & $1.25(0.22)$ \\
\hline & Rest $1^{\mathrm{b}}$ & $1.44(0.26)$ & $1.69(0.30)$ \\
\hline & Rest 2 & $1.40(0.23)$ & $1.56(0.19)$ \\
\hline & Rest 3 & $1.35(0.17)$ & $1.45(0.17)$ \\
\hline & Rest 4 & $1.42(0.25)$ & $1.38(0.17)$ \\
\hline & Average Rest & $1.40(0.18)$ & $1.53(0.16)$ \\
\hline & Average Whole & $1.26(0.11)$ & $1.39(0.19)$ \\
\hline
\end{tabular}

a indicates significant effect by 'set/rest period' for pairwise comparisons (1 vs 4)

b indicates significant effect by 'set/rest period' for pairwise comparisons (1 vs 3 ) 


\section{Table 4(on next page)}

Mean (SD) for blood lactate results 
1 Table 4. Mean (SD) for blood lactate results.

\begin{tabular}{llcc}
\hline Variable & Period & Leg Press & Recumbent Cycle Ergometer \\
\hline $\begin{array}{l}\text { Blood Lactate } \\
\left(\text { mmol. } .^{-1}\right)\end{array}$ & Rest & & $2.74(1.57)$ \\
& Set $1^{\mathrm{a}}$ & $8.63(4.04)$ & $6.84(3.26)$ \\
& Set 2 ${ }^{\mathrm{b}, \mathrm{c}}$ & $8.55(4.11)$ & $8.34(3.39)$ \\
& Set 3 & $9.40(3.74)$ & $10.02(2.81)$ \\
& Set 4 & $11.97(3.37)$ & $11.61(3.87)$ \\
& Average Sets & $9.68(3.39)$ & $9.88(2.88)$
\end{tabular}

2 a indicates significant effect by 'set/rest period' for pairwise comparisons (1 vs 4)

3 b indicates significant effect by 'set/rest period' for pairwise comparisons (2 vs 3)

4 c indicates significant effect by 'set/rest period' for pairwise comparisons (2 vs 4)

5

6

7 


\section{Table 5 (on next page)}

Mean (SD) for energy expenditure results for sets, rest periods, and totals 
1 Table 5. Mean (SD) for energy expenditure results for sets, rest periods, and totals

\begin{tabular}{|c|c|c|c|}
\hline Variable & Period & Leg Press & Recumbent Cycle Ergometer \\
\hline \multirow{6}{*}{$\begin{array}{l}\text { Aerobic } \\
\text { Energy } \\
\text { Expenditure } \\
\text { (Kcal) }\end{array}$} & Set 1 & $7.99(3.04)$ & $11.08(2.83)$ \\
\hline & & & \\
\hline & Set 2 & $8.18(3.08)$ & $11.58(2.39)$ \\
\hline & Set 3 & $8.18(3.06)$ & $12.12(2.65)$ \\
\hline & Set 4 & $8.77(4.23)$ & $12.03(2.62)$ \\
\hline & Total Sets & $34.36(13.83)$ & $46.82(9.83)$ \\
\hline \multirow{5}{*}{$\begin{array}{l}\text { Anaerobic } \\
\text { Energy } \\
\text { Expenditure } \\
\text { (Kcal) }\end{array}$} & Set $1^{\mathrm{a}}$ & $7.54(4.96)$ & $4.99(4.09)$ \\
\hline & Set $2^{\mathrm{d}}$ & $7.54(5.45)$ & $7.02(4.87)$ \\
\hline & Set 3 & $8.71(5.4)$ & $9.33(3.54)$ \\
\hline & Set 4 & $11.95(4.73)$ & $11.43(5.46)$ \\
\hline & Total Sets & $36.30(21.57)$ & $32.76(16.14)$ \\
\hline \multirow{11}{*}{$\begin{array}{l}\text { Total Energy } \\
\text { Expenditure } \\
\text { (Kcal) }\end{array}$} & Set $1^{\mathrm{a}}$ & $15.53(7.22)$ & $16.07(4.85)$ \\
\hline & Set $2^{\mathrm{c}, \mathrm{d}}$ & $15.72(8.00)$ & $18.60(6.02)$ \\
\hline & Set 3 & $16.89(7.99)$ & $21.45(5.27)$ \\
\hline & Set 4 & $20.71(8.27)$ & $23.46(6.55)$ \\
\hline & Total Sets & $68.85(30.80)$ & $68.21(35.46)$ \\
\hline & Rest $1^{b}$ & $25.86(6.04)$ & $28.65(3.31)$ \\
\hline & Rest 2 & $26.41(7.91)$ & $30.46(3.56)$ \\
\hline & Rest 3 & $26.52(6.09)$ & $31.04(4.34)$ \\
\hline & Rest 4 & $26.02(4.85)$ & $29.28(3.00)$ \\
\hline & Total Rest & $105.93(26.49)$ & $115.57(9.70)$ \\
\hline & Total Whole & $176.59(58.67)$ & $195.15(21.53)$ \\
\hline
\end{tabular}

a indicates significant effect by 'set/rest period' for pairwise comparisons (1 vs 4)

b indicates significant effect by 'set/rest period' for pairwise comparisons (1 vs 3 )

c indicates significant effect by 'set/rest period' for pairwise comparisons (2 vs 3 )

d indicates significant effect by 'set/rest period' for pairwise comparisons (2 vs 4) 


\section{Table 6 (on next page)}

Mean (SD) pre, post and changes for muscle thickness 
1

2 Table 6. Mean (SD) pre, post and changes for muscle thickness.

\begin{tabular}{lccc}
\hline Condition & Pre $\mathrm{Q}_{\mathrm{t}}(\mathrm{cm})$ & Post $\mathrm{Q}_{\mathrm{t}}(\mathrm{cm})$ & Change $\mathrm{Q}_{\mathrm{t}}(\mathrm{cm})$ \\
\hline Leg Press & $5.23(1.00)$ & $5.66(0.98)$ & $0.43(0.53)$ \\
Recumbent Cycle Ergometer & $5.01(1.01)$ & $5.66(1.04)$ & $0.66(0.61)$ \\
\hline
\end{tabular}

3

4

5 
Figure 1

Comparison across sets, and between conditions, for mean RMS amplitude (A), peak RMS amplitude (B), and iEMG (C) - Mean (SD) 

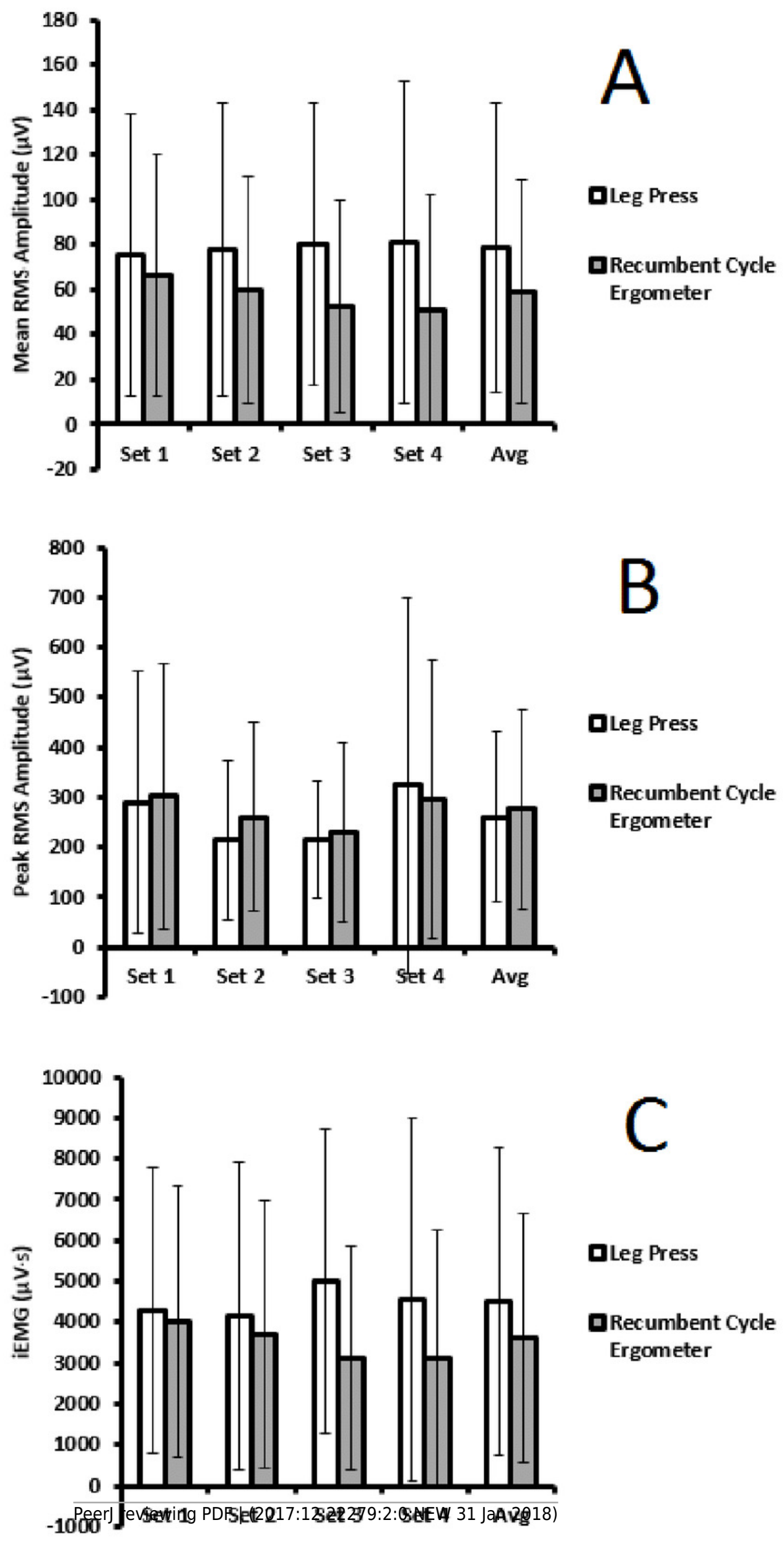
Figure 2

Comparison across sets, and between conditions for perceived effort (A), and perceived discomfort (B) - Mean (SD) 

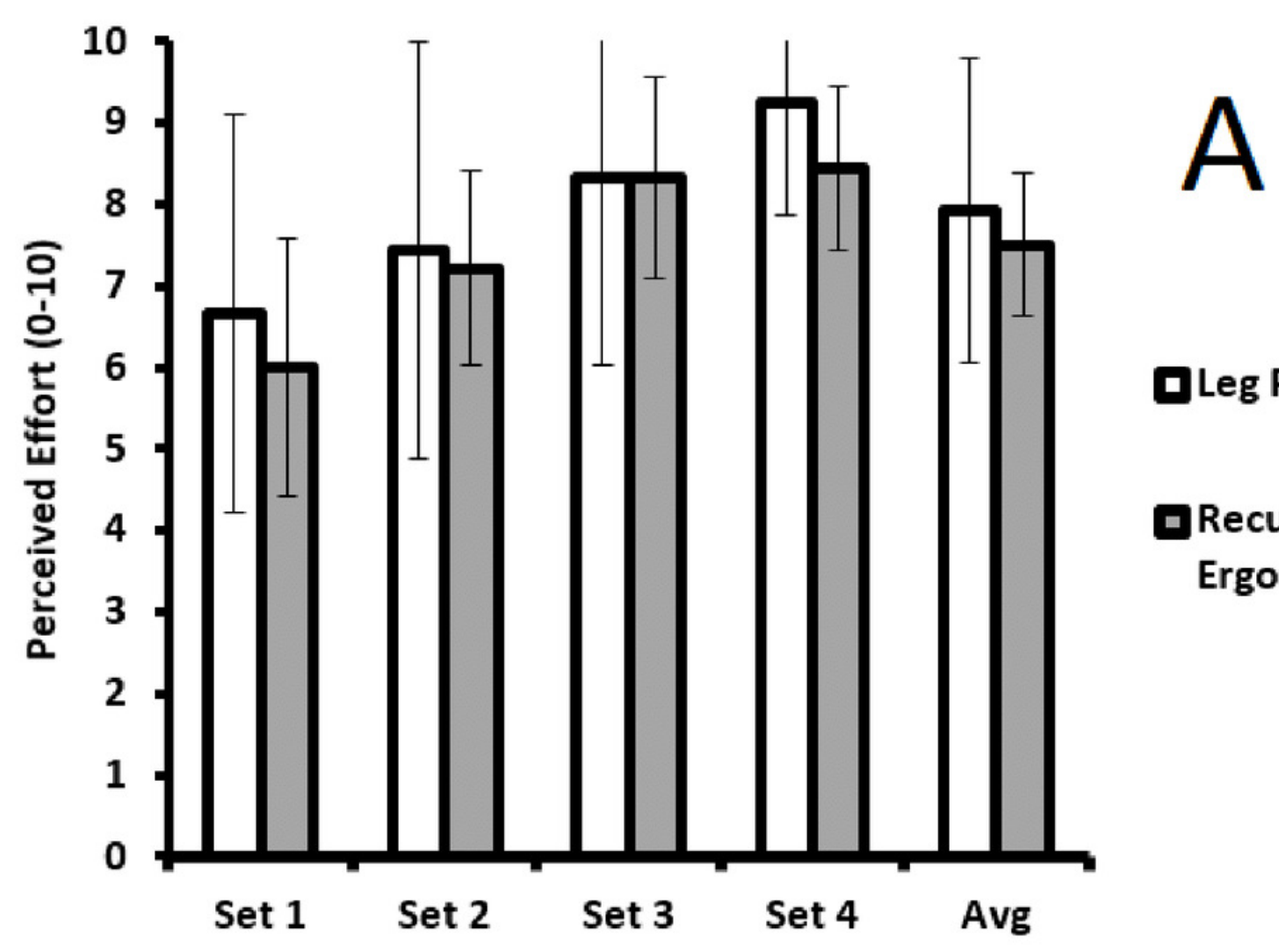

DLeg Press

- Recumbent Cycle Ergometer

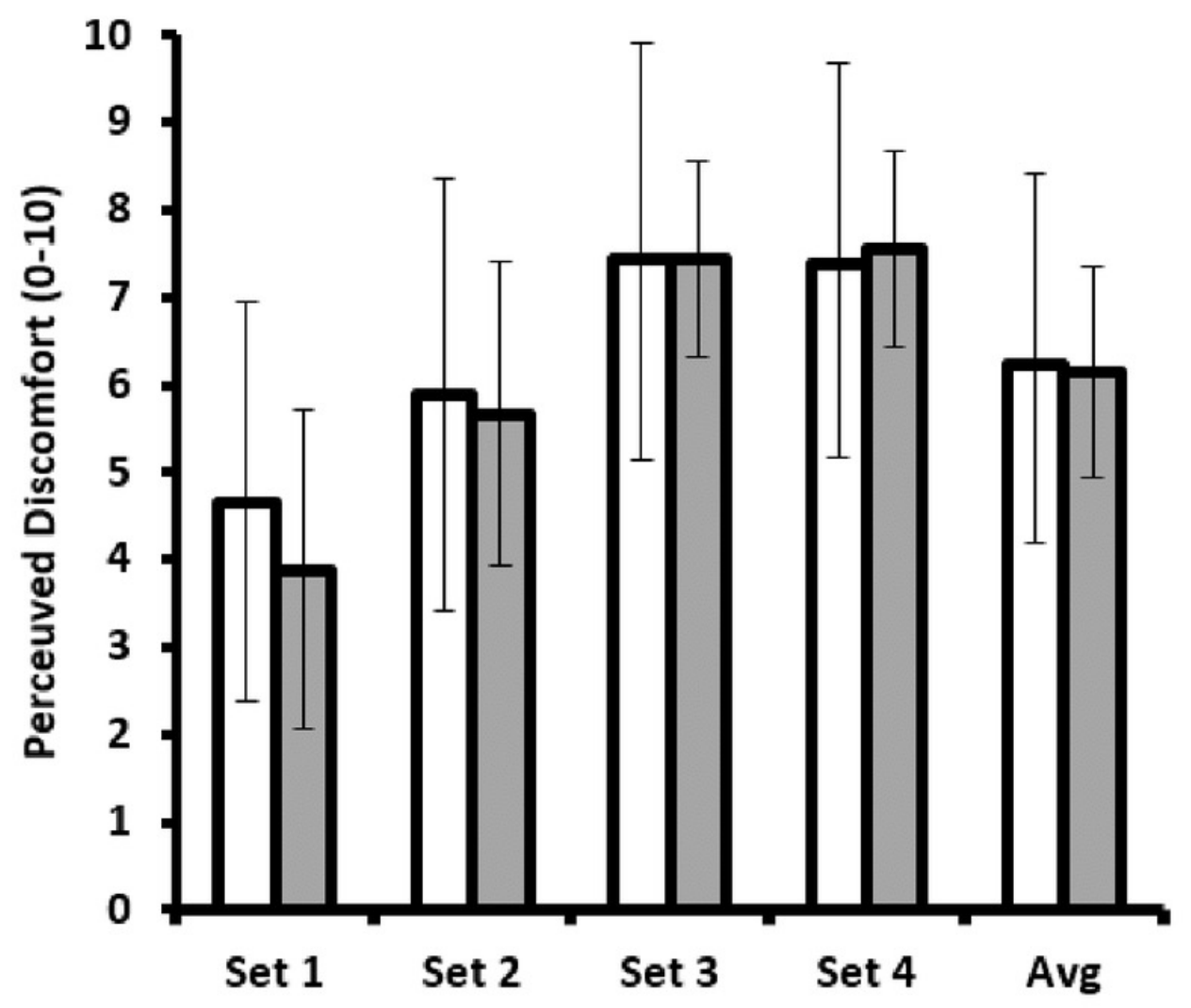

B

DLeg Press

Recumbent Cycle Ergometer 